\title{
EROSÃO EM ÁREAS DE ENCOSTA COM SOLOS FRÁGEIS E SUA RELAÇÃO COM A COBERTURA DO SOLO
}

\author{
Erosion in billside areas with fragile soils and their relation to soil cover
}

\author{
Jean Michel Moura-Bueno1*; Ricardo Simão Diniz Dalmolin²; Pablo Miguel3; ${ }^{3}$ Taciara Zborowski Horst ${ }^{4}$ \\ ${ }^{1}$ Doutorando em Ciência do Solo; Universidade Federal de Santa Maria;*jeanbueno1@gmail.com \\ *Autor pra correspondência \\ 2 Professor Associado, Universidade Federal de Santa Maria; dalmolin@ufsm.br \\ ${ }_{3}^{3}$ Professor Adjunto; Universidade Federal de Pelotas; pablo.ufsm@gmail.com \\ ${ }^{4}$ Doutoranda em Ciência do Solo; Universidade Federal de Santa Maria; tacihorst@gmail.com
}

Artigo enviado em 06/07/2017, aceito em 05/03/2018 e publicado em 10/04/2018.

\begin{abstract}
Resumo - A literatura sobre o processo erosivo no Brasil em áreas de encosta com topografia complexa e em condições naturais são incipientes. Considerando que solos de áreas de encosta apresentam maior fragilidade frente ao processo erosivo, o uso da terra nessas áreas tem efeito significativo na redução das perdas de solo e água? Pensando nisso, o presente trabalho teve como objetivo avaliar as perdas de solo e água em diferentes usos da terra e classes de solos em áreas de encosta. O estudo foi executado em três áreas (A1, A2 e A3) na região do Rebordo do Planalto do Estado do Rio Grande do Sul. Nas áreas 1 e 2 predominam Neossolos Litólicos e na A2 Argissolo Bruno-Acinzentado. Duas parcelas com superfície útil de $0,5 \mathrm{~m}^{2}$ e declividade entre 19 a $21 \%$ foram instaladas em cada área uso da terra, sendo eles floresta nativa (FN), campo nativo (CN) e lavoura (LA). As chuvas erosivas foram avaliadas durante 12 meses. As maiores perdas de solo e água foram observadas nos meses de abril, agosto e outubro, devido o maior volume e intensidades das chuvas. A maior taxa de erosão foi no uso LA, seguido dos usos CA e FN. As perdas de solo e água na LA foram: A2 112,55 Mg ha-1 e 333,73 mm; A1 13,36 Mg ha-1 e 422,30 mm; A3 79,71 Mg ha-1 e 481,04 mm. As maiores perdas de solo ocorreram na classe Argissolo Bruno-Acinzentado. A cobertura do solo teve efeito significativo na redução das perdas de solo e água em áreas de encosta com solos frágeis.
\end{abstract}

Palavras-chave - agricultura familiar, solos de encosta, topografia complexa, usos da terra.

\begin{abstract}
The literature on the erosion process in Brazil in hillside areas with complex topography and in natural conditions is incipient. Considering that the soils of hillside areas show greater fragility of the erosive process, the question is if the land use have a significant effect on reducing soil and water losses in hillside areas? the present study goal to evaluate soil and water losses in different land uses and soil classes in hillside areas. The study was carried out in three areas (A1, A2 and A3) in the region of the of the Plateau of Rio Grande do Sul State. In areas 1 and 2 predominate Entisols and A2 Ultisols. Two plots with a useful surface area of $0.5 \mathrm{~m}^{2}$ and slope between 19 and $21 \%$ were installed in each land use area, being native forest (NF), native pasture (NP) and farming (FA). The erosive rains were evaluations during 12 months. The highest losses of soil and water were observed in the months of april, august and october, due to the greater volume and intensities of the rains. The highest erosion rate was in LA use, followed by CA and FN uses. The losses of soil and water in FA were: A2 $112.55 \mathrm{Mg}$ ha-1 and $333.73 \mathrm{~mm}$; A1 $13.36 \mathrm{Mg}$ ha-1 and $422.30 \mathrm{~mm}$; A3 79.71 Mg ha-1 and $481.04 \mathrm{~mm}$. The highest soil losses occurred in the class Ultisols. Soil cover had a significant effect on the reduction of soil and water losses in hillside areas with fragile soils.
\end{abstract}

Keywords - family farms, hillside soils, complex topographic, land use types.

\section{INTRODUÇÃO}

A erosão do solo é uma séria ameaça à manutenção da vida no planeta. Estudo realizado pela Organização das Nações Unidas para Alimentação e Agricultura (FAO) revelou que 33\% dos solos de todo o mundo estão degradados em decorrência de diversos fatores, entre eles, o processo erosivo acelerado. Estudos recentes no Brasil mostram que mudanças no uso da terra vêm aumentando a degradação do solo, consequência do processo erosivo (OLIVEIRA et al., 2015; OCHOA et al., 2016; WANG et al., 2016). As consequências desse processo comprometem 


\author{
REVISTA SCIENTIA AGRARIA \\ Versão On-line ISSN 1983-2443 \\ Versão Impressa ISSN 1519-1125 \\ SA vol. $19 \mathrm{n}^{\circ} .1$ Curitiba Jan/Mar 2018 p. 102-112
}

severamente os recursos naturais com forte impacto na segurança alimentar, na resiliência da biodiversidade e manutenção dos sistemas produtivos (BERENDSE et al., 2015; OCHOA et al., 2016; WANG et al., 2016).

No Brasil, a erosão causada pela água da chuva é a forma mais significativa de degradação do solo, com perdas que variam de $0,1 \mathrm{t}$ ha-1 até $136,0 \mathrm{t}$ ha-1 conforme o uso e cobertura do solo (ANACHE et al., 2017). Para entender melhor o processo erosivo, pesquisas têm sido realizadas para determinar as taxas de erosão do solo usando parcelas de monitoramento em muitos países (GARCÍA-RUIZ et al., 2015; DURÃES; MELLO, 2016; OCHOA et al., 2016; ANACHE et al., 2017). Porém, no Brasil a maior parte dos trabalhos que estudam o processo erosivo são executados em áreas com relevo suave a ondulado, onde predominam solos profundos e atividade agrícola de grande escala, com o objetivo principal de calibrar parâmetros para a Equação Universal de Perdas de Solo (EUPS) ou sua versão modificada (MUSLE) (BARRETO et al., 2009; BAGATINI et al., 2011; DURÃES; MELLO, 2016).

Estudos sobre a magnitude do processo erosivo em nível de campo sob diferentes tipos de solo e usos da terra no Brasil ainda é escassa (OLIVEIRA et al., 2015; ANACHE et al., 2017). A falta de informações sobre a erosão é evidente quando se trata de regiões com relevo forte ondulado a montanhoso, em que a complexidade da paisagem condiciona uma grande variabilidade de solos, compondo um ecossistema frágil. Em regiões assim, se encontra uma parcela significativa de pequenas Unidades de Produção Familiar (UPF), cultivando áreas de baixa aptidão agrícola e com fortes restrições morfopedológicas (pedregosidade, rochosidade e pequena profundidade efetiva) (PEDRON et al., 2009; SAMUEL-ROSA et al., 2011). Cabe salientar que a produção familiar desempenha um papel socioeconômico fundamental no Brasil, produzindo em média $60 \%$ dos alimentos consumidos no país (IBGE, 2006).

A erosão nas áreas de encosta pode resultar em perdas significativas do potencial agrícola e consequentemente econômico, podendo causar danos muitas vezes irreversíveis ao meio ambiente e comprometer a qualidade de vida da população. Estudo realizado na bacia hidrográfica do Arroio Vacacaí Mirin na região do Rebordo do Planalto do Rio Grande do Sul atenta para risco de assoreamento da barragem de captação de água, responsável por $60 \%$ do abastecimento de água para o município de Santa Maria RS (DILL et al., 2004), apontando uma redução de $30 \%$ da capacidade de armazenamento de água da barragem.
Estudo de Miguel (2010) mostra a aplicação da EUPS para essa mesma região, em que foram observados valores de perda de solo estimados maiores que $50 \mathrm{Mg}$ ha-1ano-1 em 36\% da área e menores que esse valor em $64 \%$ da área. O autor observou que o uso da terra tem efeito significativo na redução da taxa de erosão, como os menores valores observados em floresta nativa. Além disso, os autores relatam que aplicação de modelos para estimar a produção de sedimentos na região podem superestimar os resultados devido à calibração de modelos em condições distintas dos locais de aplicação, consequência da falta de dados em áreas de encosta (BELLINASO; PAIVA, 2007). Ainda, esses modelos desconsideram as diferentes classes de solo que ocorrem na região, consequência da falta de dados de perdas de solo em diferentes solos.

Neste contexto, avaliar as perdas de solo e água por erosão em nível de campo em áreas de encosta com predomínio de solos frágeis é essencial devido a importância econômica e ambiental que estes ambientes apresentam. Assim, esforços precisam ser convergidos para caracterização do processo erosivo nestas áreas que podem vir a subsidiar estudos futuros mais aprofundados. Considerando a hipótese que os solos de áreas de encosta apresentam maior fragilidade frente ao processo erosivo, o uso da terra tem efeito significativo na redução das perdas de solo e água nessas áreas de encosta? Pensando nisso, o presente trabalho teve como objetivo avaliar as perdas de solo e água em solos frágeis sob diferentes usos da terra em áreas de encosta com sistema de produção familiar.

\section{MATERIAL E MÉTODOS}

A área de estudo envolve a sub-bacia do Menino Deus I, a qual faz parte da bacia hidrográfica do Arroio Vacacaí Mirim, situada no Rebordo do Planalto do Estado do RS, com coordenadas UTM centrais 22 J $229489 \mathrm{~m}$ (E) e $6718530 \mathrm{~m}$ (S) (Figura 1). O clima segundo classificação de Köeppen é Cfa (subtropical úmido, sem estação seca definida), com precipitação média anual de $1.707 \mathrm{~mm}$ (ALVARES et al., 2013). O padrão de chuva predominante é avançado, caracterizado por ter seu pico de maior intensidade no início da precipitação (MEHL et al., 2001). A região é caracterizada por apresentar relevo plano a montanhoso, onde predominam Neossolos Litólicos (MIGUEL et al., 2011), rasos, pedregosos onde a baixa taxa de infiltração de água é regulada pela espessura do horizonte A, fraturas do saprólito e uso do solo (PEDRON et al., 2009; STÜRMER et al., 2009). 

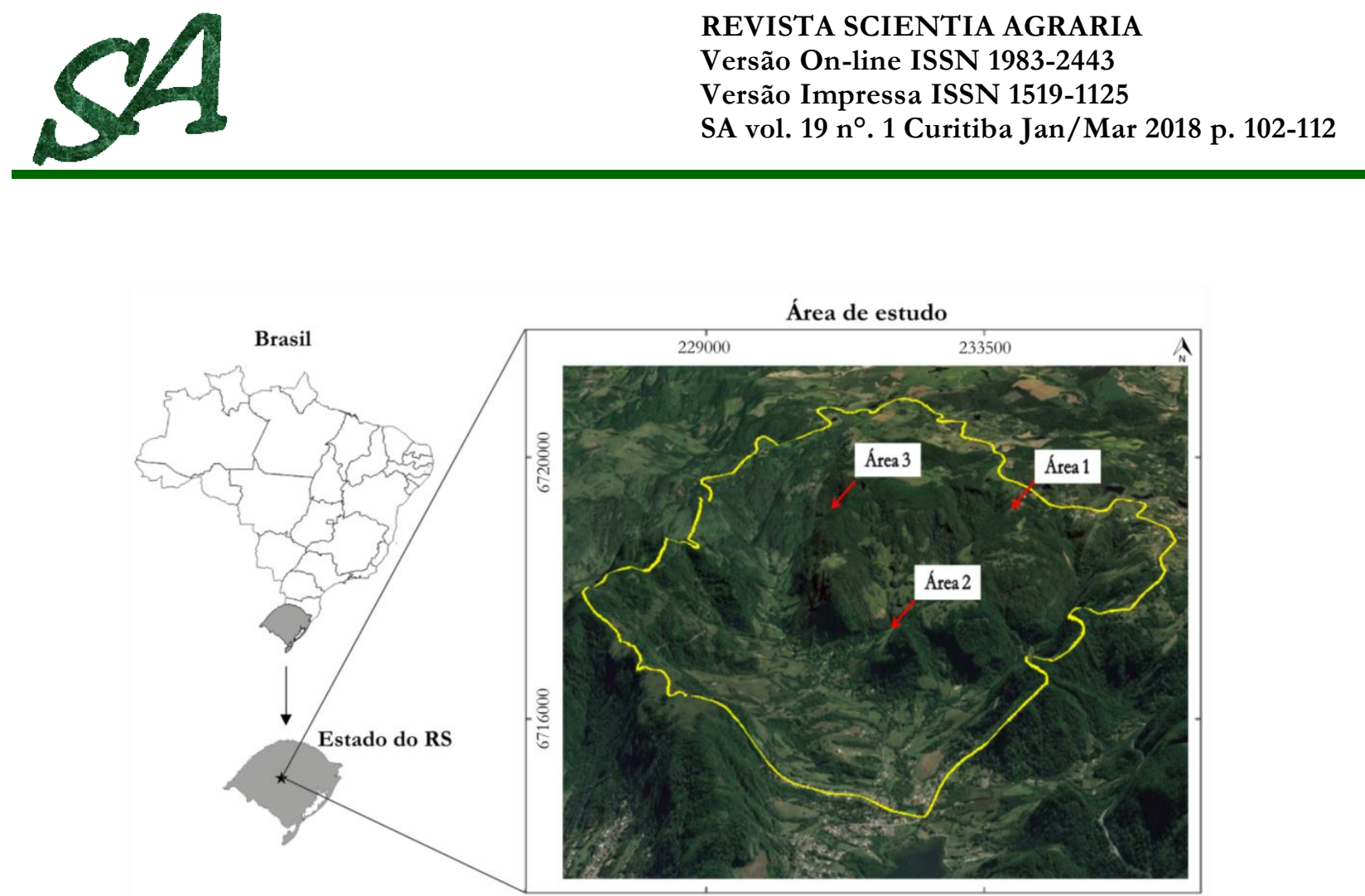

Figura 1. Localização da sub-bacia Menino Deus I no Estado do RS e indicação das três áreas de monitoramento.

O monitoramento das perdas de solo e água foi avaliado durante o período de dezembro de 2012 até dezembro de 2013, totalizando 12 meses. As parcelas foram instaladas em três locais da sub-bacia hidrográfica, denominados de área 1 (A1), área 2 (A2) e área 3 (A3). O critério de escolha dessas áreas foi baseado na representatividade dessas classes na bacia de captação, em que os Neossolos Litólicos ocorrem em 50,5\% da área e os Argissolos Bruno-Acinzentados em 14\% (MIGUEL et al., 2011). Na A1 predomina os Neossolos Litólicos Eutróficos fragmentários, derivados do basalto - formação Serra Geral sequência superior. $\mathrm{Na}$ A2 Argissolos BrunoAcinzentados Distróficos abrúpticos, derivados de arenito - formação Caturrita e Botucatu. Na A3 Neossolos Litólicos Distróficos fragmentários, derivados do basalto - formação Serra Geral sequência inferior. Os Neossolos apresentam sequência de horizontes A-Cr-R enquanto o Argissolo possui a sequência de horizontes A1-A2-Bt-C. Considerando os principais usos da terra na região de estudo, foram avaliados os mais representativos, sendo eles: floresta nativa $(\mathrm{FN})$, campo nativo $(\mathrm{CN})$ e lavoura (LA) (MIGUEL et al., 2011). Os dados referentes a caracterização do solo das três áreas de monitoramento são apresentados na Tabela 1.

O difícil acesso as áreas de monitoramento (ausência de estradas e elevada declividade do terreno), aliado ao tamanho reduzido das UPF da região inviabilizaram a instalação de parcelas padrões da EUPS (3,50 $\mathrm{m}$ de largura e 22,10 $\mathrm{m}$ de comprimento) para o monitoramento das perdas de solos e água. Neste caso, optou-se por parcelas com superfície útil de $0,5 \mathrm{~m}^{2}(0,50 \mathrm{~m} \times 1,00 \mathrm{~m})$, em que o maior comprimento obedeceu ao sentido do declive, variando de 19 a 21\%, sendo a mais representativa da área (MIGUEL et al., 2011). Essas parcelas de tamanho reduzido são utilizadas para estimar a erosão com simuladores de chuva (ALVES SOBRINHO et al., 2003). Assim, foram instaladas duas parcelas experimentais para cada uso da terra FN, CN e LA nas três áreas A1, A2 e A3.

A parcela nas áreas de LA foram mantidas com o solo totalmente descoberto durante todo o período de estudo, simulando o sistema de plantio convencional adotado nas UPF. Nas áreas de $\mathrm{CN}$ foram realizadas operações de corte da vegetação na altura de $10 \mathrm{~cm}$, para manter a mesma cobertura do solo durante todo o período de estudo. O CN da A1 é composto por varias espécies de leguminosas e gramíneas. Na A2 esse uso é composto apenas por gramíneas. A A3 apresenta gramíneas em maior quantidade e algumas leguminosas, porém, a porcentagem de cobertura do solo é menor em relação as A1 e A2. As áreas de FN foram mantidas sob condições naturais, com vegetação corresponde a Floresta Estacional Subtropical, sendo composta por espécies de pequeno, médio e grande porte.

Devido à falta de estações meteorológicas em cada área, o volume de chuva foi quantificado por pluviômetros, instalados junto de cada parcela de monitoramento. Os volumes quantificados de cada mês nas três áreas foram comparados com os volumes registrados pela Estação de Meteorologia de Santa Maria (EMSM) e com a média histórica dos últimos 30 anos (1961 a 1990), com objetivo de avaliar a variação entre os locais e o período de monitoramento em relação aos dados históricos. 
Tabela 1. Caracterização química e física dos solos das três áreas monitoradas.

\begin{tabular}{|c|c|c|c|c|c|c|c|c|c|c|}
\hline \multirow{3}{*}{$\begin{array}{c}\text { Uso } \\
\text { da } \\
\text { terra }^{1}\end{array}$} & \multirow{3}{*}{$\begin{array}{l}\mathrm{PF}^{2} \\
\mathrm{~cm}\end{array}$} & \multirow{3}{*}{$\begin{array}{c}\mathrm{CO}^{3} \\
\% \\
\end{array}$} & \multicolumn{4}{|c|}{ Granulometria } & \multirow{2}{*}{$\mathrm{P}^{4}$} & \multirow{2}{*}{$\mathrm{M}^{5}$} & \multirow{2}{*}{$\mathrm{Mi}^{6}$} & \multirow{3}{*}{$\begin{array}{c}\mathrm{Ks}^{7} \\
\mathrm{~mm} \mathrm{~h}{ }^{-1}\end{array}$} \\
\hline & & & \multirow[t]{2}{*}{ Areia total } & \multirow{2}{*}{$\begin{array}{l}\text { Areia fina } \\
\qquad \mathrm{g} \mathrm{kg}^{-1}\end{array}$} & \multirow[t]{2}{*}{ Silte } & \multirow[t]{2}{*}{ Argila } & & & & \\
\hline & & & & & & & \multicolumn{3}{|c|}{$\mathrm{cm}^{3} \mathrm{~cm}^{-3}$} & \\
\hline \multicolumn{11}{|c|}{ Área1 - Neossolo Litólico } \\
\hline \multirow{2}{*}{$\mathrm{FN}$} & $0-5$ & 8,9 & 327 & 155 & 424 & 249 & \multirow{2}{*}{0,72} & \multirow{2}{*}{0,33} & \multirow{2}{*}{0,39} & \multirow{2}{*}{697,57} \\
\hline & $5-10$ & 4,2 & 248 & 168 & 517 & 235 & & & & \\
\hline \multirow{2}{*}{$\mathrm{CN}$} & $0-5$ & 4,2 & 291 & 142 & 472 & 337 & \multirow[b]{2}{*}{0,65} & \multirow[b]{2}{*}{0,27} & \multirow[b]{2}{*}{0,38} & \multirow[b]{2}{*}{174,32} \\
\hline & $5-10$ & 2,3 & 287 & 189 & 387 & 326 & & & & \\
\hline \multirow{2}{*}{ LA } & $0-5$ & 2,0 & 239 & 140 & 412 & 348 & \multirow{2}{*}{0,65} & \multirow{2}{*}{0,30} & \multirow{2}{*}{0,35} & \multirow{2}{*}{415,15} \\
\hline & $5-10$ & 1,4 & 192 & 126 & 430 & 378 & & & & \\
\hline \multicolumn{11}{|c|}{ Área 2 - Argissolo Bruno-Acinzentado } \\
\hline \multirow{2}{*}{$\mathrm{FN}$} & $0-5$ & 5,6 & 873 & 572 & 65 & 63 & 052 & 029 & 023 & 28716 \\
\hline & $5-10$ & 3,0 & 877 & 623 & 60 & 63 & 0,52 & 0,29 & & $28 /, 10$ \\
\hline$C \mathrm{~N}$ & $0-5$ & 2,3 & 894 & 625 & 58 & 49 & 052 & 026 & 026 & 19450 \\
\hline CN & $5-10$ & 1,9 & 874 & 620 & 67 & 59 & 0,52 & 0,20 & $0, \angle 0$ & 194,59 \\
\hline & $0-5$ & 0,9 & 903 & 622 & 50 & 47 & & & & \\
\hline LA & $5-10$ & 0,6 & 893 & 607 & 56 & 50 & & 0,30 & & \\
\hline $\mathrm{LAs}^{8}$ & - & - & - & - & - & - & 0,43 & 0,20 & 0,23 & 142,04 \\
\hline & & & & rea 3 - Neos & lo Lit & & & & & \\
\hline & $0-5$ & 1,7 & 477 & 290 & 331 & 192 & & & & \\
\hline $\mathrm{FN}$ & $5-10$ & 0,6 & 383 & 272 & 415 & 202 & 0,06 & 0,30 & 0,36 & 362,85 \\
\hline & $0-5$ & 0,6 & 498 & 376 & 296 & 206 & & & & \\
\hline $\mathrm{CN}$ & $5-10$ & 0,5 & 521 & 410 & 299 & 180 & 0,56 & 0,19 & 0,37 & 69,29 \\
\hline I A & $0-5$ & 0,5 & 505 & 396 & 338 & 157 & 057 & 024 & 033 & 18 \\
\hline$L A$ & $5-10$ & 0,3 & 475 & 379 & 382 & 143 & 0,31 & 0,24 & 0,כ3 & 185,31 \\
\hline
\end{tabular}

${ }^{1}$ floresta nativa (FN); campo nativo (CN); lavoura (LA); ${ }^{2}$ profundidade; ${ }^{3}$ carbono orgânico do solo; ${ }^{4}$ porosidade (P); ${ }^{5}$ macroposidade $(\mathrm{M}) ;{ }^{6}$ microporosidade (Mi); ${ }^{7}$ condutividade hidráulica saturada (Ks); ${ }^{8}$ mostra do uso da terra lavoura com selamento superficial (LAs).

As coletas da enxurrada foram realizadas após cada evento pluviométrico individual erosivo, definido como um evento separado de outro por um intervalo de no mínimo 6 horas com precipitação inferior a 1 $\mathrm{mm}$ e quando apresentou precipitação superior a 10 $\mathrm{mm}$ ou $6 \mathrm{~mm}$ em 15 minutos (MEHL et al., 2001). Foram quantificadas as perdas de solo, água e saprolito (rocha de basalto em processo de intemperismo presente na fração grosseira da classe dos Neossolos). Em cada evento monitorado o volume de solo e água perdidos por erosão foi fracionado para reduzir o volume e uma alíquota foi coletada e encaminhada ao laboratório para quantificação. $O$ índice de erosividade das chuvas (EI) para cada mês foi calculado segundo Bertoni e Lombardi Neto (2012) conforme a seguinte equação:

$$
E I=67,355\left(\frac{r^{2}}{P}\right) 0,85
$$

em que: EI é a média mensal do índice de erosividade em MJ mm ha-1 h-1, r é a precipitação média mensal, em mm, e P é a precipitação média anual, em mm.

\section{RESULTADOS E DISCUSSÃO}

O volume de precipitação médio anual das três áreas monitoradas foi de $1397 \mathrm{~mm}$, sendo menor que a normal climatológica (1961 a 1990) para a região de Santa Maria (RS) que é de $1687 \mathrm{~mm}$. Os maiores volumes de chuva ocorreram no período de outubro a abril e no mês de agosto, representado $77 \%$ da precipitação anual. Nos meses de fevereiro, abril, agosto e outubro o volume de chuva foi maior que os dados normais, inferior nos meses de janeiro, março e dezembro e sem registro de chuva nos dois últimos meses (Figura 2A). Os eventos de precipitação que ocorreram nos meses de fevereiro e abril correspondem a chuvas de alta erosividade para o período de monitoramento. Nos demais meses as chuvas foram consideradas de média erosividade, exceto para os meses de agosto e outubro em que foram registradas chuvas de alta erosividade (Figura 2B), associados a altos volumes (Figura 2A). Os volumes de chuva também apresentaram diferenças em relação à EMSM, que registrou valor anual de 1220 $\mathrm{mm}$. Essa variação observada no volume de precipitação mostra a importância do monitoramento local para essa região. Segundo Buriol et al. (2013), variações nas precipitações mensais na bacia do Rio 
Vacacaí são normais, em que os autores mostram que para ter uma razoável precisão nos totais mensais de precipitação pluvial, são necessários de 25 a 36 anos de observação.
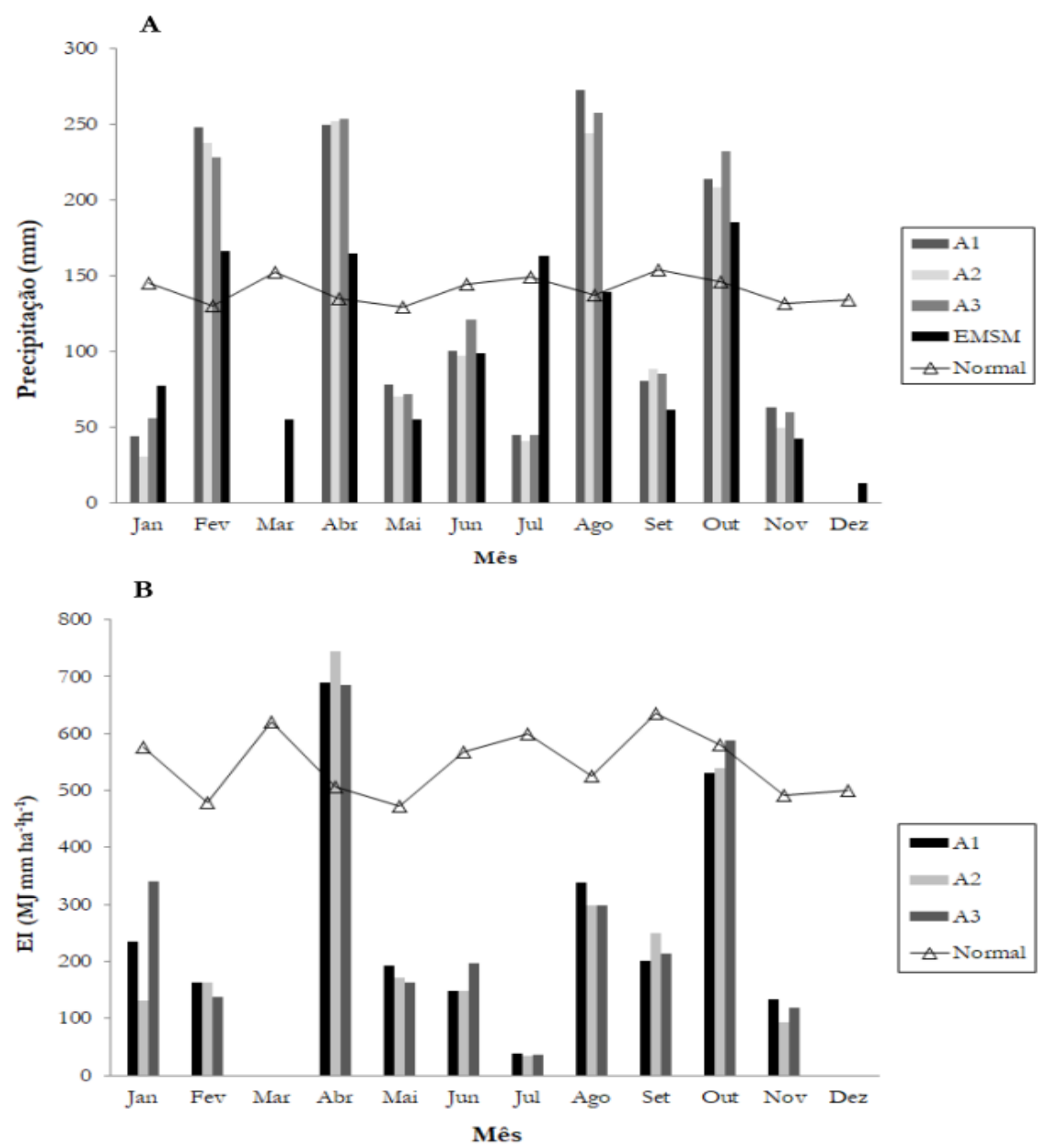

Figura 2. Precipitação média nas três áreas monitoras, estação meteorológica de Santa Maria (EMSM) e os valores normais para a região (A) e valores do índide de erosividade das chuvas (EI) para as três áreas monitoradas e valores normais (B).

Em relação aos volumes de chuva nas três áreas monitoradas, foram observadas diferenças entre os volumes mensais e totais de precipitação entre as áreas e os usos da terra de cada área. Isso ficou mais evidente no uso $\mathrm{FN}$ da $\mathrm{A} 1$, em que foram observados valores totais baixos de precipitação $(842 \mathrm{~mm}) \mathrm{em}$ relação ao mesmo uso das A2 (1135 mm) e A3 (1289 $\mathrm{mm}$ ) (Tabela 4). As variações mensais dos volumes de precipitação e as diferença entre os volumes entre as áreas e uso da terra mostra a variabilidade das precipitações na sub-bacia de captação, mesmo em pequenas distâncias. Essas variações estão associadas ao micro clima em algumas áreas na bacia pela influência do relevo plano a montanhoso, refletindo no volume e intensidade das chuvas, indo ao encontro das informações descritas em Buriol et al. (2013).

As diferenças nos volumes das precipitações em cada área refletiram na variação da erosividade das chuvas (EI), que apresentou valores anuais de 2.672, 2.574 e $2.780 \mathrm{MJ}$ mm ha-1 h-1 na área A1, A2 e A3, respectivamente. Nos meses de abril, agosto e outubro ocorrem os maiores valores de EI com valores de 690; 339; $531 \mathrm{MJ} \mathrm{mm}$ ha-1 h-1 na A1; 744; 298; $539 \mathrm{MJ} \mathrm{mm}$ ha-1 h-1 na A2 e 685; 298; 588 MJ mm ha-1 h-1 na A3, respectivamente para os três meses (Figura 2B). Cogo et al. (2006) determinaram o EI a partir da análise de 1607 chuvas erosivas no período de 1963 a 2000 para o município de Santa Maria, obtendo o valor médio de $\mathrm{EI}=7.866 \mathrm{MJ} \mathrm{mm}$ ha-1 h-1. Os autores concluíram que o período onde ocorrem os maiores valores de EI 


\author{
REVISTA SCIENTIA AGRARIA \\ Versão On-line ISSN 1983-2443 \\ Versão Impressa ISSN 1519-1125 \\ SA vol. $19 \mathrm{n}^{\circ} .1$ Curitiba Jan/Mar 2018 p. 102-112
}

é de outubro a abril, representando $56 \%$ da precipitação e $69 \%$ da EI. No presente estudo, foram observados valores altos de precipitação e EI nesses mesmos meses e também no mês de agosto, correspondendo a $77 \%$ da EI.

Os resultados observados de volume e EI das chuvas indicam que o comportamento anual e mensal dos eventos erosivos apresenta uma grande variação dentro na bacia hidrográfica do presente estudo. As variações de precipitação e EI das chuvas em pequenas escalas na área tornam o estudo do processo erosivo mais complexo, pois esses fatores implicam diretamente na variação das perdas de solo e água (BOIX-FAYOS et al., 2006). Assim, para melhor entender as interações entre os fatores relacionados o processo erosivo, Anache et al. (2017) apontam para a necessidade de avalições continuas em todos território brasileiro, principalmente em regiões onde existe escassez de dados.

A perda de água em relação ao total precipitado apresentou os maiores valores na LA, seguido dos usos $\mathrm{CN}$ e FN nas três áreas, com maiores perdas nos meses de maior volume de chuva (Tabela 2). $O$ mês de fevereiro, em exceção, apresentou volumes altos de precipitação associados a valores baixos de perda de água, provavelmente relacionado a baixa erosividade das chuvas.

As maiores perdas de solo para as três classes de solos avaliadas foram observadas no uso da terra LA, seguido dos usos CN e FN (Tabela 3). Na A1 a LA apresentou um perda total de solo (PTS) de $13,36 \mathrm{Mg}$ ha-1, CN 0,07 Mg ha-1 e FN 0,03 Mg ha-1. As maiores perdas foram observadas nos meses de abril, agosto e outubro no uso da terra LA, devido a maior erosividade das chuvas nesses meses (Figura 2B). Na A2 a PTS no uso LA foi $112,55 \mathrm{Mg}$ ha-1, no $\mathrm{CN}$ de $0,35 \mathrm{Mg}$ ha- 1 e a FN de 0,06 Mg ha-1, com as maiores perdas nos meses de fevereiro, abril, agosto e outubro nos três usos. $\mathrm{Na}$ A3 foi de $79,71 \mathrm{Mg}$ ha-1 na LA, seguido de 0,28 Mg ha-1 no $\mathrm{CN}$ e $0,05 \mathrm{Mg}$ ha- 1 na $\mathrm{FN}$, com os maiores valores nos meses de janeiro, fevereiro, abril, agosto e outubro (Tabela 3).

Os processos que regem esses valores de perda de solo estão relacionados a ausência de cobertura do solo na LA, o qual favoreceu para que ocorresse o processo acelerado de desagregação das partículas do solo causado pelo impacto da gota de chuva sobre o solo descoberto. Associado à isso, ocorre o fenômeno de salpicamento das partículas dispersadas, causando a obstrução dos poros e formação do selamento superficial, reduzindo a taxa de infiltração de água (LEITE et al., 2009) promovendo aumento da enxurrada, implicando em maiores perda de solo e água nas áreas de LA, sendo isso observado com maior destaque no uso LA da A2 (Tabela 1).
As maiores perdas de solo encontrada nas lavouras vão de encontro ao estudo de Miguel et al. (2014) conduzido nessa mesma área, em que foi observado que a principal fonte de geração de sedimentos são áreas em que o solo encontra-se descoberto ou com reduzida cobertura do solo. Da mesma forma, Guimarães et al. (2011), avaliando a erosão do solo em uma microbacia no Estado de Santa Catarina, observaram que a cobertura dos solo por áreas de floresta nativa foi o fator responsável reduzir as taxas de perda de solo. Resultados encontrados por Berendse et al. (2015) mostraram a relação entre a diversidade de espécies e resistência do solo ao processo erosivo em área de encosta, em que a manutenção e restauração da diversidade de plantas contribuem para minimizar a erosão e manter a fertilidade do solo. Didoné et al. (2014) avaliando o impacto do sistemas agrícolas na produção de sedimentos em duas bacias hidrográficas no sul do Brasil, constatou que áreas com solos profundos e relevo suave ondulado apresentaram coeficiente de escoamento de $14 \%$ e geração de $140 \mathrm{Mg}$ ha-1 ano-1, e em áreas com relevo ondulado e solos raso a profundos foi verificado coeficiente de escoamento de $31 \%$ e geração de $270 \mathrm{Mg}$ ha-1 ano-1. Os autores observaram que a falta de práticas conservacionistas nas áreas de lavoura é a principal causa do processo erosivo acelerado e consequente produção de sedimentos nas bacias estudadas.

Nos usos CN e FN as perdas de solo e água são significativamente menores em relação a LA, sendo observada redução da perda de solo de $48 \% \mathrm{CN}$ e $78 \%$ $\mathrm{FN}$ na $\mathrm{A} 1,68 \% \mathrm{CN}$ e $98 \% \mathrm{FN}$ na $\mathrm{A} 2$ e $65 \% \mathrm{CN}$ e $95 \% \mathrm{FN}$ na A3 em relação ao uso LA. Esses resultados corroboram com os observados por Oliveira et al. (2015), que avaliaram o fator cobertura do solo em condições naturais e agrícolas, em que observaram redução das perdas de solo em locais com maior cobertura. Revisão realizada por Anache et al. (2017) de meta-dados de estudos de escoamento superficial e erosão do solo sob chuva natural no Brasil, mostram redução de $45 \%$ das taxas de erosão e escoamento em áreas não alteradas e com vegetação nativa em relação a áreas de pastagens em plantio convencional. A importância da cobertura do solo na redução das taxas de erosão também foi relata em estudo de Wang et al. (2016) na China dos anos 80 até 2010, em que as maiores taxas de erosão estão relacionados a ecossistemas frágeis que sofreram mudanças no uso terra.

As perdas de solo e água foram maiores no $\mathrm{CN}$ comparado a FN, devido ao efeito do dossel vegetativo da floresta na dissipação da energia cinética da gota de chuva por ser mais significativo, devido a maior estatura e diversificação de espécies. Além disso, 
na FN o acúmulo de serrapilheira e presença de canais biológicos formados pela fauna solo contribuem para aumentar infiltração de água no perfil (STÜRMER et al., 2009). Isto é confirmado pelos maiores valores de Ks nas áreas de FN (Tabela 1) refletindo nas menores perdas de água. No uso $\mathrm{CN}$ da $\mathrm{A} 3$ é observado o menor valor de Ks (Tabela 1) devido à compactação causada pelo pisoteio de bovinos presentes na área resultando nos maiores valores de perda de água em relação às outras áreas (Tabela 2).

Tabela 2. Perda de água e precipitação mensal e total para os três usos da terra nas avaliados nas três áreas.

\begin{tabular}{|c|c|c|c|c|c|c|c|c|c|}
\hline \multirow{3}{*}{ Mês } & \multicolumn{6}{|c|}{ Perda de Água por enxurrada } & \multicolumn{3}{|c|}{ Precipitação } \\
\hline & \multicolumn{2}{|c|}{ LA } & \multicolumn{2}{|c|}{$\mathrm{CN}$} & \multicolumn{2}{|c|}{$\mathrm{FN}$} & \multirow[t]{2}{*}{ LA } & \multirow{2}{*}{$\mathrm{CN}$} & \multirow{2}{*}{$\mathrm{FN}$} \\
\hline & $\mathrm{mm}$ & $\% 1$ & $\mathrm{Mm}$ & $\%$ & $\mathrm{~mm}$ & $\%$ & & & \\
\hline \multicolumn{10}{|c|}{ ÁREA 1 - Neossolo Litólico } \\
\hline Janeiro & 1,82 & 0,43 & 0,54 & 0,87 & 0,35 & 2,83 & 44 & 43 & 30 \\
\hline Fevereiro & 5,58 & 1,32 & 2,01 & 3,25 & 0,97 & 7,85 & 248 & 256 & 128 \\
\hline Março & 0,00 & 0,00 & 0,00 & 0,00 & 0,00 & 0,00 & 0 & 0 & 0 \\
\hline Abril & 139,74 & 33,09 & 19,30 & 31,17 & 2,19 & 17,72 & 250 & 250 & 157 \\
\hline Maio & 4,63 & 1,10 & 0,75 & 1,21 & 0,39 & 3,16 & 78 & 82 & 38 \\
\hline Junho & 5,41 & 1,28 & 1,17 & 1,89 & 0,64 & 5,18 & 100 & 101 & 52 \\
\hline Julho & 2,64 & 0,63 & 0,63 & 1,02 & 0,49 & 3,96 & 45 & 47 & 25 \\
\hline Agosto & 69,95 & 16,56 & 26,81 & 43,30 & 2,27 & 18,37 & 273 & 291 & 160 \\
\hline Setembro & 4,68 & 1,11 & 1,64 & 2,65 & 0,60 & 4,85 & 80 & 96 & 56 \\
\hline Outubro & 183,90 & 43,55 & 7,74 & 12,50 & 2,34 & 18,93 & 214 & 218 & 151 \\
\hline Novembro & 4,24 & 1,00 & 1,33 & 2,15 & 2,11 & 17,07 & 63 & 62 & 45 \\
\hline Dezembro & 0,00 & 0,00 & 0,00 & 0,00 & 0,00 & 0,00 & 0 & 0 & 0 \\
\hline Total & 422,30 & 100,0 & 61,91 & 100,0 & 12,36 & 100,0 & 1395 & 1446 & 842 \\
\hline \multicolumn{10}{|c|}{ ÁREA 2 - Argissolo Bruno-Acinzentado } \\
\hline Janeiro & 13,95 & 4,18 & 0,43 & 0,23 & 1,19 & 2,45 & 30 & 30 & 28 \\
\hline Fevereiro & 9,17 & 2,75 & 4,39 & 2,38 & 5,24 & 10,81 & 238 & 216 & 211 \\
\hline Março & 0,00 & 0,00 & 0,00 & 0,00 & 0,00 & 0,00 & 0 & 0 & 0 \\
\hline Abril & 90,25 & 27,04 & 40,78 & 22,13 & 15,90 & 32,80 & 252 & 245 & 215 \\
\hline Maio & 7,11 & 2,13 & 0,13 & 0,07 & 1,14 & 2,35 & 70 & 65 & 57 \\
\hline Junho & 11,82 & 3,54 & 0,59 & 0,32 & 2,06 & 4,25 & 97 & 98 & 83 \\
\hline Julho & 6,92 & 2,07 & 0,00 & 0,00 & 0,80 & 1,65 & 41 & 40 & 39 \\
\hline Agosto & 59,88 & 17,94 & 65,87 & 35,74 & 5,83 & 12,03 & 244 & 238 & 205 \\
\hline Setembro & 14,22 & 4,26 & 0,00 & 0,00 & 1,59 & 3,28 & 88 & 84 & 72 \\
\hline Outubro & 113,94 & 34,14 & 69,28 & 37,59 & 10,86 & 22,40 & 208 & 208 & 182 \\
\hline Novembro & 6,49 & 1,94 & 2,82 & 1,53 & 3,87 & 7,98 & 49 & 50 & 45 \\
\hline Dezembro & 0,00 & 0,00 & 0,00 & 0,00 & 0,00 & 0,00 & 0 & 0 & 0 \\
\hline Total & 333,76 & 100,0 & 184,29 & 100,0 & 48,48 & 100,0 & 1317 & 1274 & 1135 \\
\hline \multicolumn{10}{|c|}{ ÁREA 3 - Neossolo Litólico } \\
\hline Janeiro & 15,83 & 3,29 & 17,91 & 3,74 & 0,99 & 4,57 & 56 & 56 & 45 \\
\hline Fevereiro & 24,68 & 5,13 & 16,89 & 3,53 & 2,13 & 9,83 & 228 & 223 & 196 \\
\hline Março & 0,00 & 0,00 & 0,00 & 0,00 & 0,00 & 0,00 & 0 & 0 & 0 \\
\hline Abril & 224,45 & 46,66 & 218,26 & 45,58 & 4,94 & 22,80 & 254 & 256 & 238 \\
\hline Maio & 4,19 & 0,87 & 0,00 & 0,00 & 0,68 & 3,14 & 72 & 74 & 68 \\
\hline Junho & 22,62 & 4,70 & 7,71 & 1,61 & 1,67 & 7,71 & 121 & 125 & 118 \\
\hline Julho & 12,44 & 2,59 & 13,56 & 2,83 & 0,49 & 2,26 & 45 & 50 & 44 \\
\hline Agosto & 77,21 & 16,05 & 47,41 & 9,90 & 4,36 & 20,12 & 258 & 268 & 232 \\
\hline Setembro & 13,04 & 2,71 & 9,58 & 2,00 & 1,18 & 5,45 & 85 & 85 & 74 \\
\hline Outubro & 75,76 & 15,75 & 134,32 & 28,05 & 3,82 & 17,63 & 232 & 232 & 216 \\
\hline Novembro & 10,01 & 2,08 & 12,88 & 2,69 & 1,42 & 6,55 & 60 & 60 & 62 \\
\hline Dezembro & 0,00 & 0,00 & 0,00 & 0,00 & 0,00 & 0,00 & 0 & 0 & 0 \\
\hline Total & 481,04 & 100,0 & 478,82 & 100,0 & 21,67 & 100,0 & 1411 & 1429 & 1289 \\
\hline
\end{tabular}

${ }^{1}$ Porcentagem foi calculado em relação ao valor total de perda de água. 
Tabela 3. Perda de solo mensal e total para os três usos da terra avaliados nas três áreas.

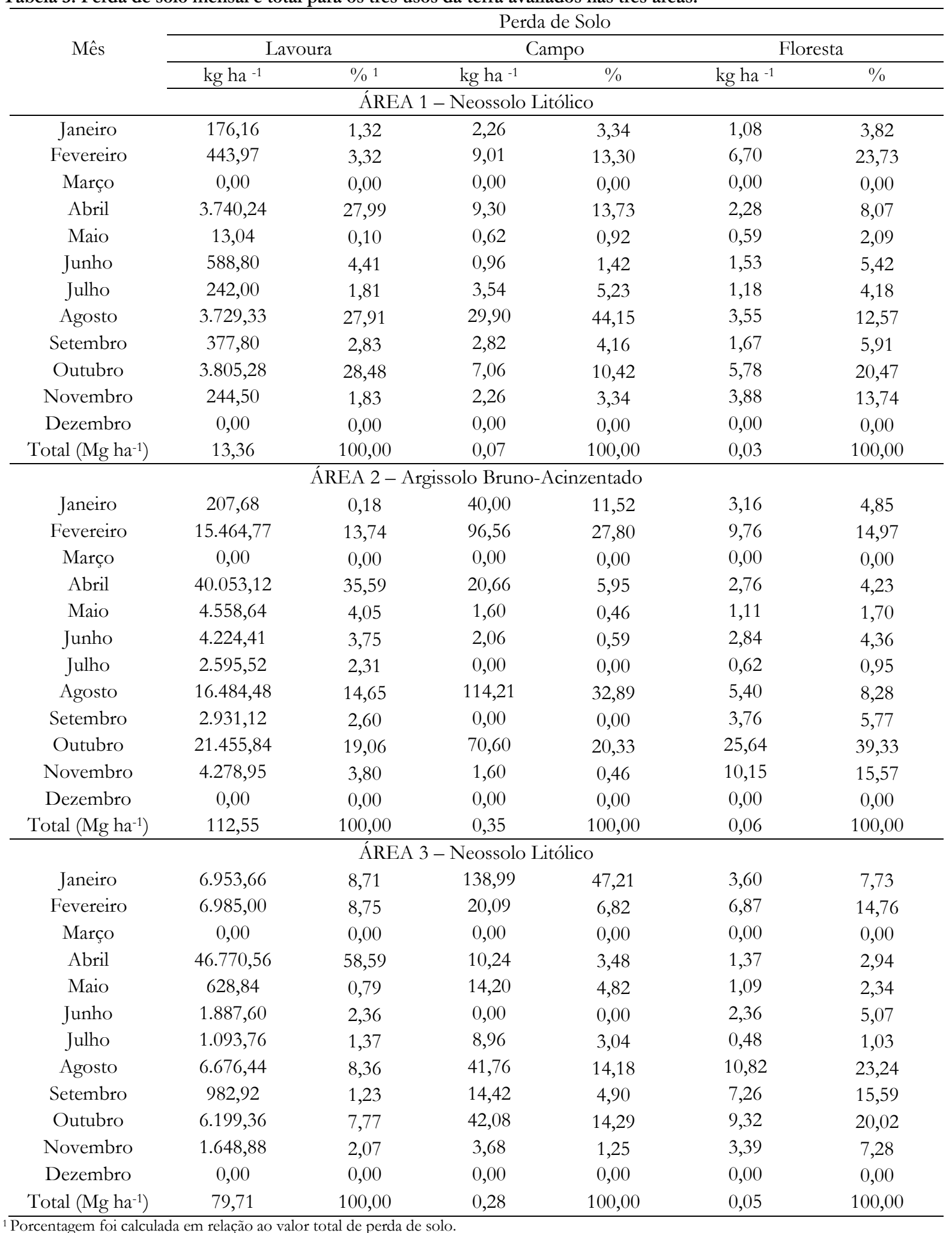




\author{
REVISTA SCIENTIA AGRARIA \\ Versão On-line ISSN 1983-2443 \\ Versão Impressa ISSN 1519-1125 \\ SA vol. $19 \mathrm{n}^{\circ} .1$ Curitiba Jan/Mar 2018 p. 102-112
}

As diferenças nas perdas de solo e água entre as três áreas, os usos da terra e tipos de solos avaliados estão relacionadas com as diferenças de precipitação, associada às características físicas e teor de carbono orgânico dos mesmos (Tabela 1). O volume de precipitação entre as áreas A1 e A3 não difere muito, exceto no uso FN, porém o Neossolo Litólico da A1 apresenta textura mais fina (silte + argila), maior teor de carbono orgânico, implicando em melhor coesão entre as partículas e menor suscetibilidade a desagregação. Além disso, essa área apresenta maior condutividade hidráulica e porosidade total em relação à A3 (Tabela 1), conferindo maior infiltração de água no solo e menor escoamento superficial. Isso explica os maiores valores de perda de água e solo (Tabela 2 e 3 ) na $\mathrm{A} 3 \mathrm{em}$ relação a $\mathrm{A} 1$, com destaque para a perda de solo de 6 vezes maior na LA e de água de 7,7 vezes maior no $\mathrm{CN}$. No $\mathrm{CN}$ da $\mathrm{A} 3$ foi observado e menor valor de Ks, sendo isso, reflexo da compactação pelo pisoteio de bovinos.

A textura arenosa na camada de $0-5 \mathrm{~cm}$ na A2 impõe menor coesão entre as partículas e grau muito fraco de estrutura, facilmente dispersada pela gota d'água e carreada pela enxurrada quando o volume de chuva excede a capacidade de infiltração do solo ou apresenta alta erosividade. A baixa condutividade hidráulica (Tabela 1) e obstrução dos poros causada pelo salpicamento resultou na formação do selamento superficial e após o secamento, a formação de uma crosta endurecida que reduziu o valor da permeabilidade do solo de $167,39 \mathrm{~mm} \mathrm{~h}-1$ para 142,04 mm h-1 (Tabela 1), resultando no valor de 112,55 Mg ha-1 de perda de solo na A2 (Tabela 3).

Em relação à perda anual de solo, os valores encontrados estão acima dos mencionados pela FAO, onde perdas de solo de $12,5 \mathrm{Mg}$ ha-1 ano-1 são aceitáveis para solos profundos e perdas entre 2 e 7,3 $\mathrm{Mg}$ ha-1 ano para solos pouco profundos. No presente estudo, a classe de solo Argissolo na A2, apresentou na área de LA uma perda de solo de $112,55 \mathrm{Mg}$ ha-1 ano1 , valor quase dez vezes maior que o aceitável. As classes de solos Neossolo (A1) com 13,36 Mg ha-1 ano-1 e Neossolo (A2) com 79,71 Mg ha-1 ano-1 também apresentaram valores superiores aos aceitáveis pela FAO. O potencial natural de perda de solo (PNPS) estimado pela EUPS para a região de estudo segundo Miguel (2010) é menor que $250 \mathrm{Mg}$ ha-1 ano1 em 17\% da área, 250 - $500 \mathrm{Mg}$ ha-1 ano-1 em 15\%, $500-1000 \mathrm{Mg}$ ha-1 ano-1 em 19\%, $1000-2000 \mathrm{Mg}$ ha-1 ano-1 em 28\% e > $2000 \mathrm{Mg}$ ha-1 ano-1 em 21\%, sendo os maiores PNPS registrados em áreas mais declivosas e com predomínio de solos rasos. O potencial de perda de solo (PPS) estimando pela EUPS por Miguel (2010) indica para 43\% da área PPS entre 0 - $25 \mathrm{Mg}$ ha-1 ano-1, sendo que nesse intervalo enquadra-se o valor obtido a campo na A1 $(13,36 \mathrm{Mg}$ ha-1 ano-1). Para 30\% o PPS ficou no intervalo de $25-$ $100 \mathrm{Mg}$ ha-1 ano-1, em que nessa faixa foi observada as perdas da A3 (79,71 Mg ha-1 ano-1). Em 6\% da área o PPS estimado foi entre $100-150 \mathrm{Mg}$ ha-1 ano-1, sendo o valor observado na área A2 (112,55 Mg ha-1 ano-1). Isso mostra que $79 \%$ da área de estudo apresenta perda de solo acima das aceitáveis pela FAO, sendo um indicativo da necessidade do uso de práticas conservacionistas nessas áreas.

Em decorrência dos Neossolos Litólicos da A1 e A3 apresentarem textura grosseira e grande quantidade cascalhos na camada até $10 \mathrm{~cm}$, foram quantificadas perdas de saprolito, sendo os maiores valores observados na A1 (Tabela 4).

Tabela 4. Perda de saprolito nas áreas A1 e A3 no uso da terra lavoura.

\begin{tabular}{ccccccccccccc}
\hline Área & Jan & Fev & Mar & Abr & Mai & Jun & $\begin{array}{c}\text { Jul } \\
\mathrm{kg} \mathrm{ha}^{-1}\end{array}$ & Ago & Set & Out & Nov & Dez \\
\hline A1 & 0,0 & 8,6 & 0,0 & 7,2 & 0,0 & 0,0 & 0,0 & 19,3 & 0,0 & 0,0 & 5,6 & 0,0 \\
A3 & 230,0 & 0,0 & 0,0 & $2.588,8$ & 153,9 & 265,8 & 180,3 & $1.903,2$ & 428,2 & 1221,8 & 176,6 & 0,0 \\
\hline
\end{tabular}

Levando em consideração as perdas de solo e saprolito na A1 e A3, onde estão presentes os Neossolos Litólicos, o processo erosivo pode reduzir a espessura do horizonte $A$, causando a gênese reversa em que Neossolos Regolíticos passam a Neossolos Litólicos. A hipótese de involução de classes de solo é sugerida em alguns trabalhos realizados nessa região e outras do RS (SAMUEL-ROSA et al., 2011; STRECK et al., 2008). Esses trabalhos levantam a hipótese que a taxa de formação do solo pode ser semelhante a taxa de perda de solo por erosão natural. Estudo realizado por Gracheva (2011) mostra a importância do conhecimento da erosão no que diz respeito ao controle da formação do solo para as regiões tropicais e subtropicais úmidas.

Os resultados encontrados no presente estudo indicam que medidas conservacionistas devem ser adotadas em áreas de lavoura para regiões de encosta com solos frágeis da região sul do Brasil. Além disso, mais estudos devem ser executados nessas áreas para melhor compreensão do comportamento das chuvas erosivas e do processo erosivo, permitindo o planejamento de uso do recurso natural solo, visando a mitigação da degradação do solo e contaminação dos recursos hídricos. 


\section{CONCLUSÃO}

As maiores perdas de solo e água foram observadas no uso da terra lavoura, seguidos dos usos de campo nativo e floresta, sendo os maiores valores observados na classe dos Argissolos BrunoAcinzentados.

A cobertura da terra e a presença de camadas impeditivas como Bt, contato lítico, fração grosseira, textura, condutividade hidráulica e porosidade do solo influenciaram nas diferenças de perda de solo e água entre as classes de solos.

As maiores perda de solos e água ocorrem nos meses de abril, agosto e outubro na A1 e A2, e janeiro, fevereiro, abril, agosto e outubro na A3, devido a maior erosividade das chuvas, mostrando a importância da cobertura do solo nesses períodos.

\section{AGRADECIMENTOS}

Os autores agradecem ao Conselho Nacional de Desenvolvimento Científico e Tecnológico pela suporte financeiro e concessão da bolsa PQ ao segundo autor. Os autores agradecem o Dr. Alessandro Samuel Rosa (UFSM) pela colaboração nas fases de coleta, processamento e discussão dos dados.

\section{REFERÊNCIAS}

ALVARES, C. A.; STAPE, J. L.; SENTELHAS, P. C.; GONÇALVES, J. L. M.; SPAROVEK, G. Köppen's climate classification map for Brazil. Meteorologische Zeitschrift, v.22, n.6, p.711-728, 2013.

ALVES SOBRINHO, T.; VITORINO, A. C.T; SOUZA, L. C. F.; GONÇALVES, M. C.; CARVALHO, D. F. Infiltração de pagua no solo em sistemas de plantio direto e convencional. Revista Brasileira de Engenharia Agricola e Ambiental, v.7, n.2, p.191-196, 2003.

ANACHE, J. A.; WENDLAND, E. C.; OLIVEIRA, P. T.; FLANAGAN, D. C.; NEARING, M. A. Runoff and soil erosion plot-scale studies under natural rainfall: A meta-analysis of the Brazilian experience. Catena, v. 152, p. 29-39, 2017.

BAgAtiNI, T.; COGO, N. P.; GILleS, L.; PORTELA, J. C.; PORTZ, G.; QUEIROZ, H. T. Perdas de solo e água por erosão hídrica após mudança no tipo de uso da terra, em dois métodos de preparo do solo e dois tipos de adubação. Revista Brasileira de Ciência do Solo, v. 35, n. 3, p. 999-1011, 2011.
BARRETTO, A. G. O. P.; LINO, J. S.; SPAROVEK, G. Bibliometria da pesquisa brasileira em erosão acelerada do solo: instituições, temas, espaço e cronologia. Revista Brasileira de Ciência do Solo, v. 33, n. 6, p. 1845-1854, 2009.

BELLINASO, T. B.; PAIVA, J. D. Avaliação da produção de sedimentos em eventos chuvosos em uma pequena bacia hidrográfica semi-urbana de encosta. Revista Brasileira de Recursos Hídricos, v. 12, n. 4, p. 169181, 2007.

BERENDSE, F.; VAN RUIJVEN, J.; JONGEJANS E.; KEESSTRA, S. Loss of plant species diversity reduces soil erosion resistance. Ecosystems, v. 18, n. 5, p. 881-888, 2015.

BERTONI, J.; LOMBARDI NETO, F. Conservação do solo. 8.ed. São Paulo: Ícone, 2012.

BOIX-FAYOS, C; MARTÍNEZ-MENA, M.; ARNAU-ROSALÉN, E.; CALVO-CASES, A.; CASTILLO, V.; ALBALADEJO, J. Measuring soil erosion by field plots: Understanding the sources of variation. Earth-Science Reviews, v. 78, n. 3, p. 267-285, 2006.

BURIOL, G. A.; STEFANEL, V.; SWAROWSKY, A.; DE OLIVEIRA CADEMARTORI, R. T. Homogeneidade espacial da precipitação pluvial na bacia hidrográfica do Rio Vacacaí, RS. Ciência Rural, v. 43, n. 12, p. 2160-2167, 2013.

COGO, C. M.; ELTZ, F. L. F.; CASSOL, E. A. Erosividade das chuvas em Santa Maria, RS, determinada pelo índice EI30. Revista Brasileria de Agrometeorologia, v. 14, p. 1-11, 2006.

DILL, P. R. J.; PAIVA, E. M. D.; PAIVA, J. B. D.; ROCHA, J. S. M. Assoreamento do Reservatório do Vacacaí-Mirim em Santa Maria e a sua relação com a deterioração da Bacia Hidrográfica contribuinte. Revista Brasileira de Recursos Hídricos v. 9, p. 56-64, 2004.

DIDONÉ, E. J.; MINELLA, J. P. G.; REICHERT, J. M.; MERTEN, G. JH.; DALBIANCO, L.; BARRROS, C. A. P.; RAMON, R. Impact of no-tillage agricultural systems on sediment yield in two large catchments in Southern Brazil. Journal of Soils and Sediments, v. 14, p. 1287-1297, 2014. 
DURÃES M. F.; MELLO, C. R de. Distribuição espacial da erosão potencial e atual do solo na Bacia Hidrográfica do Rio Sapucaí, MG. Engenharia Sanitária e Ambienta, v. 21, n. 4, p. 677-685, 2016.

GARCÍA-RUIZ, J. M.; BEGUERÍA, S.; NADALROMERO, E.; GONZÁLEZ-HIDALGO, J. C.; LANA-RENAULT, N.; SANJUÁN, Y. A metaanalysis of soil erosion rates across the world. Geomorphology, v. 239, p. 160-173, 2015.

GRACHEVA, R. Formation of soil diversity in the mountainous tropics and subtropics: Rocks, time, and erosion. Geomorphology, v. 135, n. 3, p. 224-231, 2011.

GUIMARÃES, R. Z.; LINGNAU, C.; RIZZI, N.E.; SCHEICHI, R. G.; BIANCHI, R. de C. Espacialização da perda de solo por erosão laminar na microbacia do Rio Campinas, Joinville, SC. Raega-O Espaço Geográfico em Análise, v. 23, 2011.

INSTITUTO BRASILEIRO DE GEOGRAFIA E ESTATÍSTICA - IBGE. Censo Agropecuário - Agricultura Familiar: primeiros resultados. Rio de Janeiro: IBGE, 2006. 267p.

Disponível em:

$<$ http://biblioteca.ibge.gov.br/visualizacao/periodicos /50/agro_2006_agricultura_familiar.pdf $>$ Acesso em: 20 mai. 2017.

LEITE, M. H. S.; COUTO, E. G.; AMORIM, S. S.A.; COSTA, E. L.; MARASCHIN, L. Perdas de solo e nutrientes num Latossolo Vermelho-Amarelo Ácrico Típico, com diferentes sistemas de preparo e sob chuva natural. Revista Brasileira de Ciência do Solo, v. 33, n. 3, p. 689-699, 2009.

MEHL, H. U.; ELTZ, F. L. F.; REICHERT, J. M.; DIDONÉ, I. A. Caracterização dos padrões de chuva ocorrentes em Santa Maria (RS). Revista Brasileira de Ciência do Solo, v. 25, p. 475 483, 2001.

MIGUEL, P. Caracterização pedológica, uso da terra $e$ modelagem da perda de solo em áreas de encosta do Rebordo do Planalto do RS. 2010. 112p. Dissertação (Mestrado em Ciência do Solo) - Universidade Federal de Santa Maria, Santa Maria, RS. 2010.

MIGUEL P.; DALMOLIN, R.S.D.; PEDRON, F. A.; SAMUEL-ROSA, A.; MEDEIROS, P. S. C.; MOURABUENO, J. M.; BALBINOT, A. Solo e dinâmica de ocupação das terras em áreas do rebordo do planalto do Rio Grande do Sul. Revista Brasileira Agrociência, Pelotas, v.17, n.4-4, p.447-455, out-dez, 2011.

MIGUEL, P.; DALMOLIN, R. S. D.;PEDRON, F. A.; MOURA-BUENO, J. M.; TIECHER, T. Identificação de fontes de produção de sedimentos em uma bacia hidrográfica de encosta. Revista Brasileira de Ciência do Solo, v. 38, p. 585-598, 2014.

OCHOA, P. A., FRIES, A., MEJÍA, D., BURNEO, J. I., RUÍZ-SINOGA, J. D., CERDÀ, A. Effects of climate, land cover and topography on soil erosion risk in a semiarid basin of the Andes. Catena, v. 140, p. 3142, 2016

OLIVEIRA, P.T.S., NEARING, M.A., WENDLAND, E. Orders of magnitude increase in soil erosion associated with land use change from native to cultivated vegetation in a Brazilian savannah environment. Earth Surface Processes and Landforms. v.40, p.1524-1532, 2015.

PEDRON, F. D. A.; AZEVEDO, A. C. D.; DALMOLIN, R. S. D.; STÜRMER, S. L. K.; MENEZES, F. P. Morfologia e classificação taxonômica de Neossolos e saprolitos derivados de rochas vulcânicas da formação serra geral no Rio Grande no Sul. Revista Brasileira de Ciência do Solo, v.33, p. 119-128, 2009.

SAMUEL-ROSA, A.; MIGUEL, P.; DALMOLIN, R. S. D.; PEDRON, F. A. Uso da terra no Rebordo do Planalto do Rio Grande do Sul. Ciência e Natura, v.33, n.1, p.161-173, 2011.

STRECK, E. V.; KÄMPF, N.; DALMOLIN, R. S. D.; KLAMT, E.; NASCIMENTO, P. C.; SCHNEIDER, P.; GIASSON, E.; PINTO, L. F. S. Solos do Rio Grande do Sul. 2.ed. Porto Alegre: EMATER/RS, 2008. 222p.

STÜRMER, S. L. K., DALMOLIN, R. S. D.; AZEVEDO, A. C.; PEDRON, F. A.; MENEZES, F. P. Relação da granulometria do solo e morfologia do saprolito com a infiltração de água em Neossolos Regolíticos do Rebordo do Planalto do Rio Grande do Sul. Ciência Rural, v. 39, n. 7, 2009.

WANG, X.; ZHAO, X.; ZHANG, Z.; YI, L.; ZUO, L.; WEN, Q.; LIU, F.; XU, J.; HU, S.; LIU, B. Assessment of soil erosion change and its relationships with land use/cover change in China from the end of the 1980s to 2010. Catena, v. 137, p. 256-268, 2016. 